\title{
Improvement of Sintering Performance of Nanosilver Paste by Tin Doping
}

\author{
Hui Yang and Jihui $W u$ \\ College of Mechanical and Control Engineering, Guilin University of Technology, Guilin, Guangxi/541006, China \\ Correspondence should be addressed to Jihui Wu; jxmjwjh@163.com
}

Received 28 October 2019; Revised 5 December 2019; Accepted 14 December 2019; Published 22 January 2020

Guest Editor: Anagh Bhaumik

Copyright (c) 2020 Hui Yang and Jihui Wu. This is an open access article distributed under the Creative Commons Attribution License, which permits unrestricted use, distribution, and reproduction in any medium, provided the original work is properly cited.

\begin{abstract}
Nanosilver paste, an interconnect solder, is a common choice in the electronics packaging industry. However, higher sintering temperature and lower sintering strength limit its application. At present, doped nanosilver paste has been studied for use in chip interconnection. In order to improve the sintering properties and shear strength of nanosilver paste, we have developed a new tin-doped nanosilver paste (referred to as silver tin paste), and according to the decomposition temperature of the organic dispersant in the slurry, a corresponding sintering process with a maximum temperature of $300^{\circ} \mathrm{C}$ was developed. The product after sintering of the silver tin paste is a mixture of a solid solution of $\mathrm{Ag}$ and an $\mathrm{Ag}_{3} \mathrm{Sn}$ phase. Among them, the hard and brittle phase $\mathrm{Ag}_{3} \mathrm{Sn}$ diffuse distribution in the silver matrix for strengthening, and the solid solution of Ag acts as a replacement solid solution strengthening. As the content of doped Sn increases, the sintering strength increases remarkably. When the Sn content is $5 \%$, the joint shear strength reaches the highest value of $50 \mathrm{MPa}$. When it exceeds $5 \%$, the sintering strength gradually decreases, which may be caused by the excessive formation of the intermetallic compound IMC as the dopant content increases. This new tin-doped nanosilver technology has the characteristics of low-temperature sintering and high-temperature service, so it is expected to be widely used in semiconductor power devices.
\end{abstract}

\section{Introduction}

At present, high-temperature power device chip bonding often uses nanosilver paste sintering method, and the joint formed by sintering of nano-Ag paste has good electrical and thermal conductivity [1], but there are also the following problems:

(1) The sintering temperature of the nano-Ag paste is in the range of $250^{\circ} \mathrm{C}$ to $350^{\circ} \mathrm{C}$. This high heating temperature is not compatible with other packaging materials [2]

(2) After the nanosilver paste is sintered, the joint shear strength is low

(3) The production cost of pure nanosilver paste is relatively high

Therefore, it is imperative to improve the sintering performance of the nanosilver paste. There are two general methods.
One method is to use a short-chain organic surfactant as a dispersing agent in the preparation of the nanosilver. Generally, such organic matter has a relatively low thermal decomposition temperature and can lower the sintering temperature. However, this makes the dispersibility of the nanosilver worse, increasing the risk of agglomeration of the nanoparticles; the other method is to reduce the particle size of the nano-Ag, and the melting point of the nanoparticles decreases with the decrease of the particle size, thereby lowering the sintering temperature. However, this makes the production process complicated and costly [3], which is not conducive to largescale industrial applications. Adding low-melting alloy elements is a good way to improve the sintering performance of nanosilver solder paste. Among the doped metals, the melting points of tin, indium, and gallium are relatively low, but the cost of indium and gallium is relatively high, so we choose nanotin as the dopant. The sintering process of tin-doped nanosilver paste is divided into four stages: dissolution, diffusion, solidification, and reaction. As the sintering temperature 

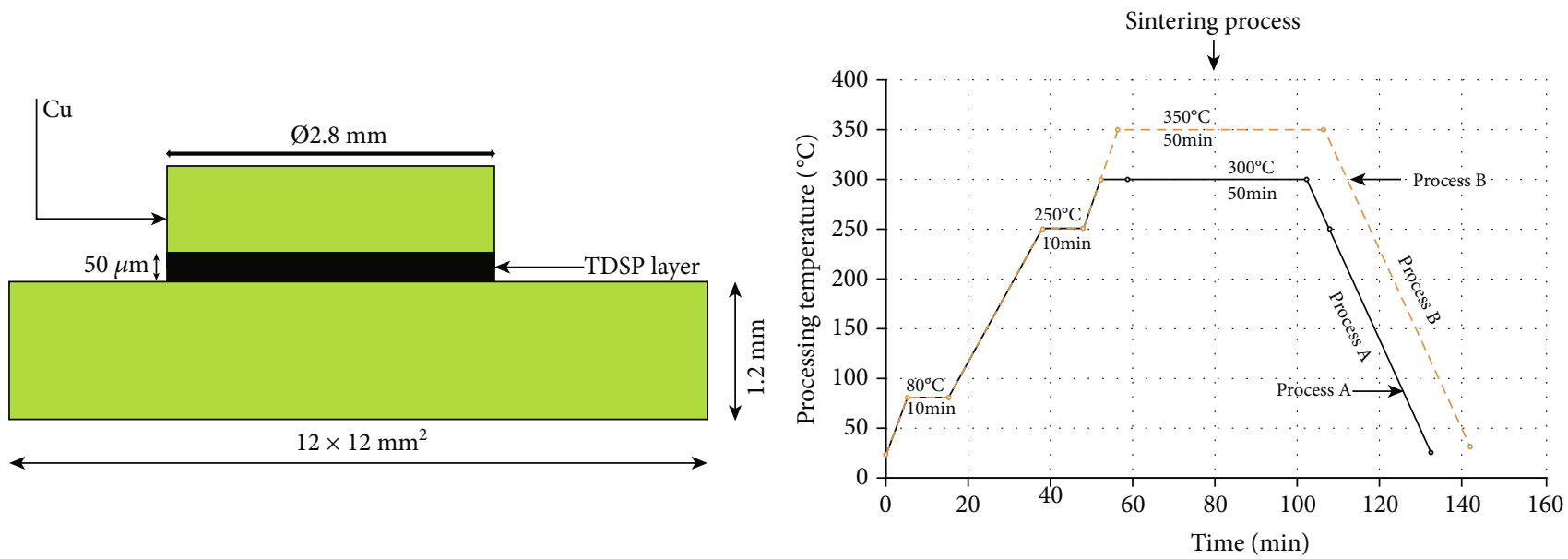

Figure 1: Silver tin paste sintering process.

increases, nanotin diffuses into the nanosilver. When the Sn melts, the diffusion speed will increase. The liquid-phase Sn will contact the solid-phase Ag, and the liquid will rise or penetrate along the gap, thus rapidly uniform diffusion in the body and leads to a lattice change of the matrix; after the solidification process, the reaction forms an intermetallic compound IMC phase. Finally, an Ag-based replacement solid solution and a uniformly distributed $\mathrm{Ag}_{3} \mathrm{Sn}$ are obtained. The Ag-based replacement solid solution acts as a solid solution strengthening, and $\mathrm{Ag}_{3} \mathrm{Sn}$ acts as a second phase to diffuse and strengthen the shear strength of the joint. Therefore, we studied the preparation process of tin-doped nanosilver paste (silver tin paste) and analyzed its sintering properties and sintering mechanism.

\section{Experiment}

2.1. Production of Silver Tin Paste. Through experiments, we have developed a new sintered solder paste, nanotin and nanosilver mixed slurry. In order to improve the stability of the nanoparticles, it is necessary to disperse the nanoparticles with a surfactant. Nonionic surfactants can be dissolved in water and organic solvents and can be strongly adsorbed on solid surfaces [4]. Cosurfactants are generally similar organic compounds with slightly different structures of surfactants [5]. The addition of the active agent makes the micelle radius smaller, thus contributing to the dispersion of the nanoparticles. Therefore, we chose polyethylene glycol 600 and glycerol as composite surfactants, mixed into nanosilver powder with about 20 nanometers in size, made nanosilver paste, and then doped nanotin powder with about 20 nanometers in size into silver paste. The mixed slurry was diluted with an organic matter ethanol (volatilization temperature of $78.3^{\circ} \mathrm{C}$ ) and sufficiently contacted by manual stirring and ultrasonic stirring to form a uniform nano-Ag-Sn mixed slurry. Then, we put it for a while to get the final silver tin slurry. In order to study the effect of tin content on silver paste, we prepared four kinds of silver tin paste with different tin content, wherein the tin content is $0 \%, 5 \%, 10 \%$, and $20 \%$. The boiling points of polyethylene glycol 600 and glycerin were $250^{\circ} \mathrm{C}$ and $290^{\circ} \mathrm{C}$, respectively, and the maximum sintering temper-

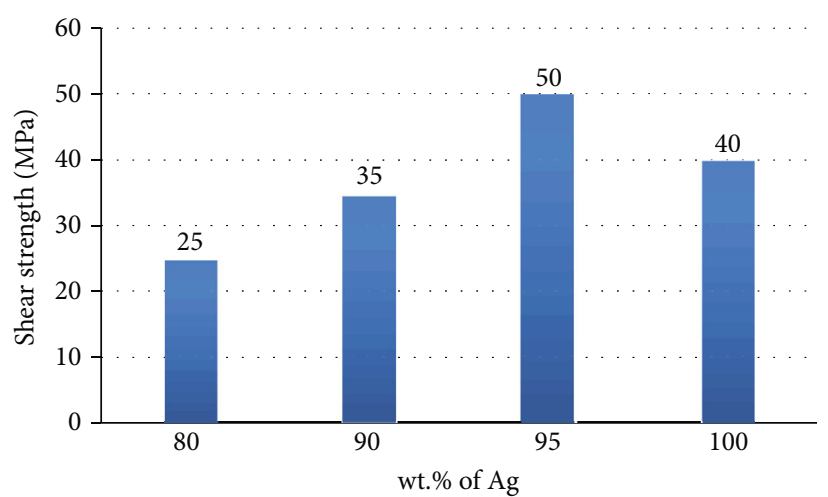

Figure 2: Shear strength of sintered $\mathrm{Ag}+\mathrm{Sn}$ joint (6 MPa sintering pressure).

ature was determined to be $300^{\circ} \mathrm{C}$ in order to sufficiently decompose during the sintering process.

2.2. Preparation of Sintering Process. In order to improve the sintering effect of the silver tin paste, the substrate and the chip are replaced by a copper plate to produce a sandwich structure. As shown in Figure 1, the upper surface is a copper plate with a diameter of $\varnothing 2.8 \mathrm{~mm}$, and the lower surface is a copper substrate having an area of $12 \times 12 \mathrm{~mm}^{2}$, and the upper and lower copper plates are joined together by a silver tin paste.

Although the silver tin paste sintering process can also have three phases (Figure 1, Process A), it is different from the pure nanosilver paste sintering process (Figure 1 Process B) [3]. The first step was maintained at $80^{\circ} \mathrm{C}$ for 10 minutes, exceeding the solvolysis temperature to allow the ethanol to fully decompose. The second step was heated to a temperature of $250^{\circ} \mathrm{C}$ for 10 minutes, exceeding the decomposition temperature of the surfactant, so that the polyethylene glycol 600 was sufficiently decomposed. The last step is heated to $300^{\circ} \mathrm{C}$, which is similar to the boiling point of glycerol, so heat to $300^{\circ} \mathrm{C}$, and keep warm for 50 minutes to ensure complete decomposition of glycerol and full diffusion and reaction of tin and silver. The increasing rate of the sintering temperature was $10^{\circ} \mathrm{C} / \mathrm{min}$. Process is operated in air rather than in a vacuum. The final cooling process is slow cooling in air. 


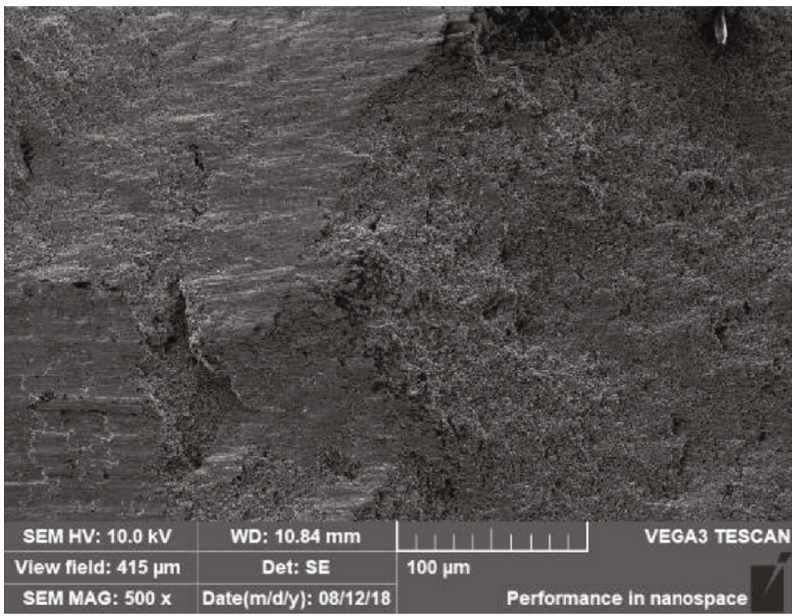

(a)

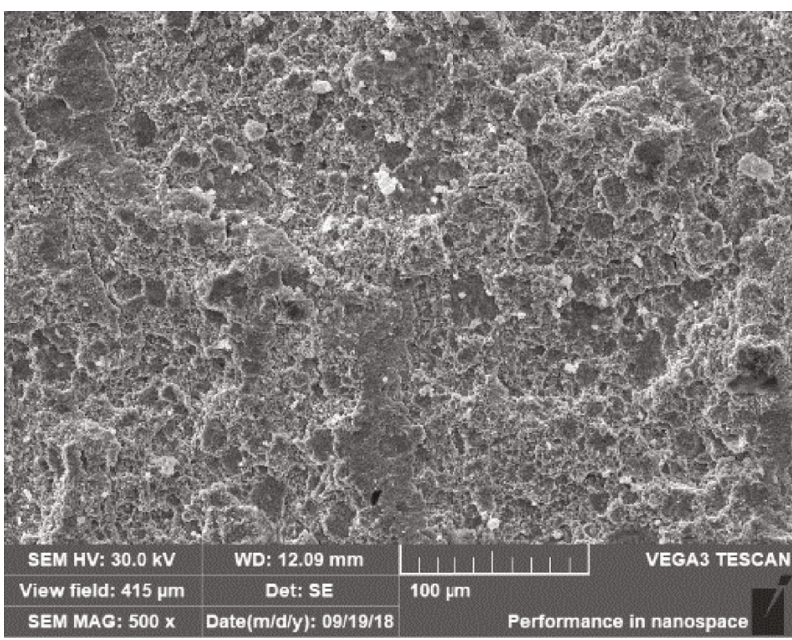

(c)

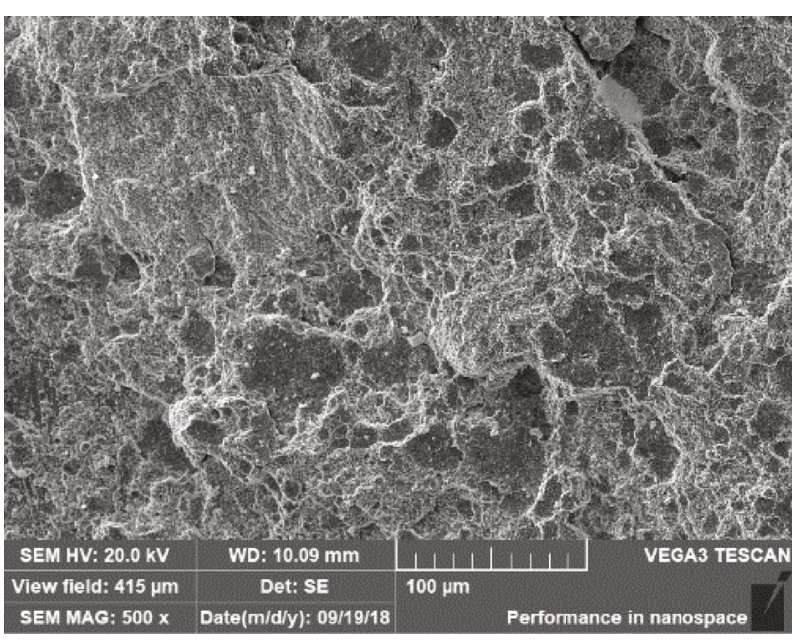

(b)

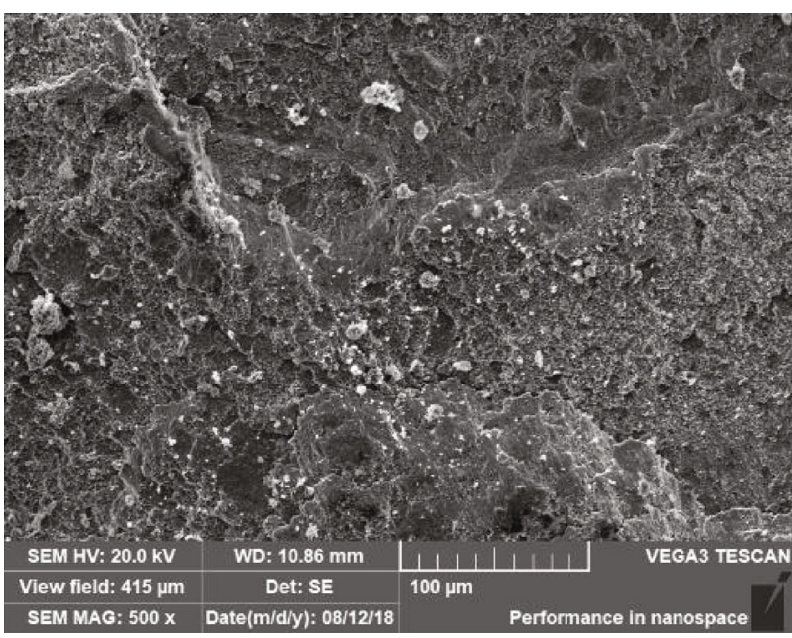

(d)

Figure 3: SEM image of various content of silver tin paste. (a) Pure Ag. (b-d) Sn content is 5\%, 10\%, and 20\%.

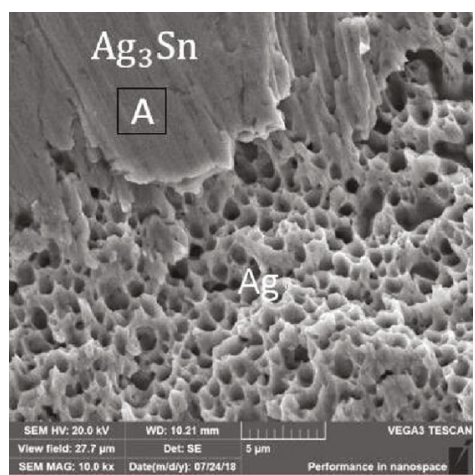

(a)

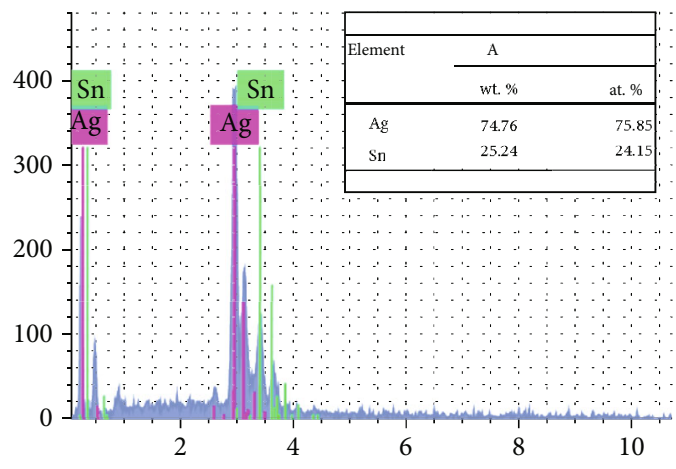

(b)

FIgURE 4: Microstructure and composition analysis of silver tin paste. (a) 10000 times SEM image of silver tin paste containing 5\% tin. (b) Partial EDS analysis.

\section{Results and Discussion}

3.1. Sintering Strength of Ag Sn Paste. In order to compare with the silver tin paste, we first performed the sintering experiment on the pure nanosilver paste and tested the shear strength of the joint using a shear tester (DAGE4000). The shear strength of the pure nanosilver paste was $40 \mathrm{MPa}$, and then the shear strength of the sintered joints of each 


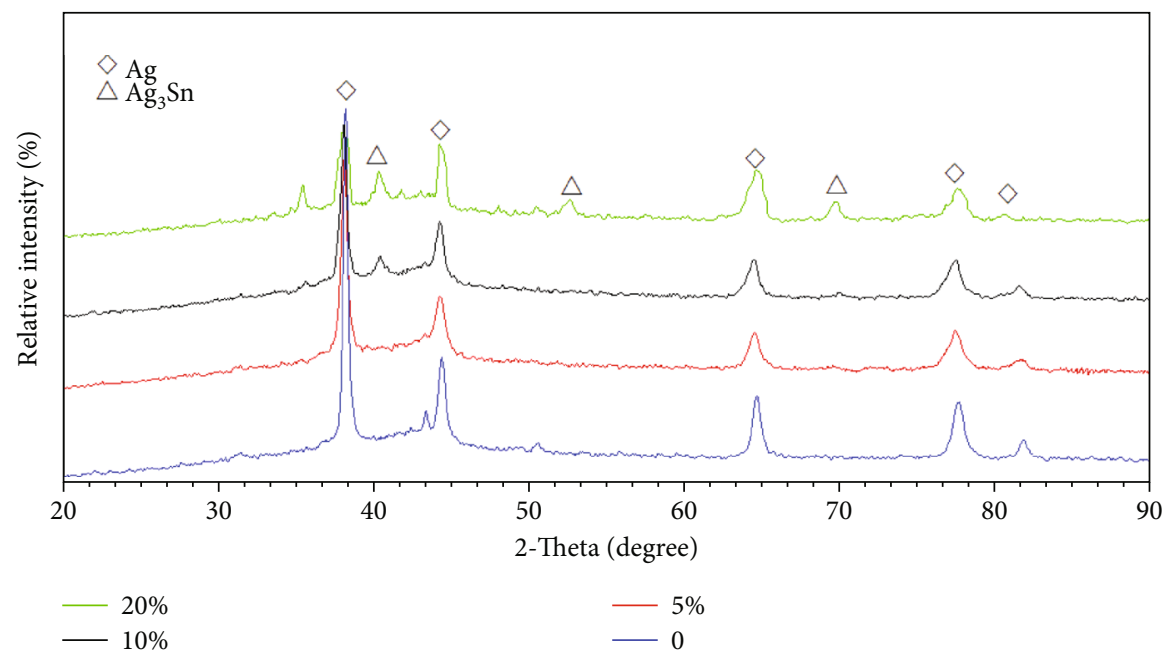

FIGURE 5: XRD pattern of various sintered silver tin paste.

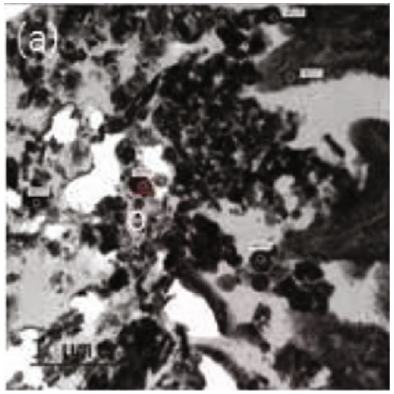

(a)

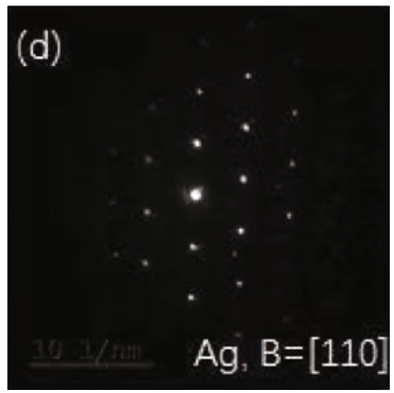

(d)

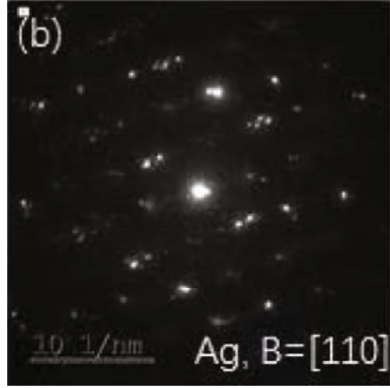

(b)

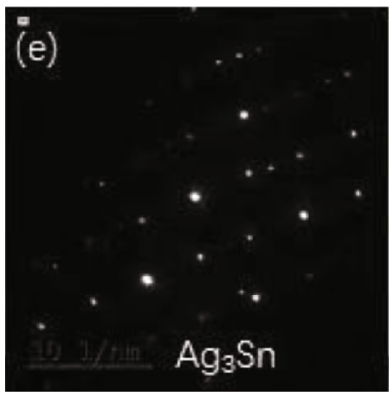

(e)

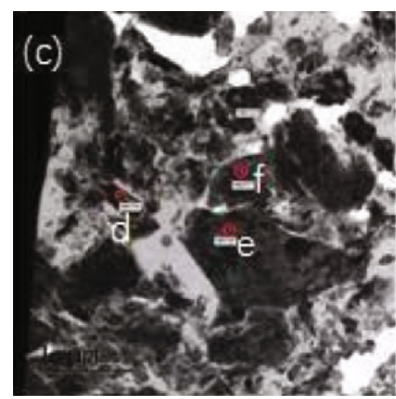

(c)

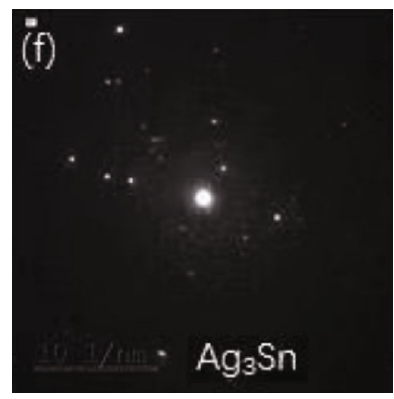

(f)

Figure 6: NBED pattern at different locations of $\mathrm{Ag}+5 \% \mathrm{Sn}$ interface.

silver tin paste containing 5\%,10\%, and $20 \%$ tin was tested. Figure 2 shows the shear strength (6 $\mathrm{MPa}$ sintering pressure) of various silver solder joints at $300^{\circ} \mathrm{C}$ sintering temperature. When the amount of $\mathrm{Sn}$ is 5\%, the shear strength reaches the highest value of $50 \mathrm{MPa}$, which is higher than the pure nano silver paste sintered joint by more than $10 \mathrm{MPa}$.

3.2. Form of Silver Tin Paste. Figure 3 shows a scanning electron microscope image of sintered silver tin paste with various tin contents. Dark areas, light areas, and some holes can be seen in the image. The larger the atomic number, the lighter the color; the atomic number of silver is 47 , and $\mathrm{Sn}$ is 50 , so $\mathrm{Sn}$ is lighter than silver. Previous experiments have shown that the dark area is the Ag matrix phase as the main phase. As the Sn content increases, the content of the light-colored area increases significantly, and whether the composition of the light-colored area is $\mathrm{Ag}_{3} \mathrm{Sn}$ or $\mathrm{Sn}$ remains to be determined. The formation of the holes is due to the decomposition of the organic polymer.

Figure $4(\mathrm{a})$ is a 10,000 times scanning electron microscope image of a silver tin paste joint containing $5 \%$ tin. In comparison with the dark-sintered morphology of pure nanosilver, it can be found that the sintered morphology of $5 \%$ silver tin paste is light and dark, and the light colored areas are sintered to be denser. The composition analysis of the denser region $\mathrm{A}$ is shown in Figure 4(b) on the right. It shows that the content of the Ag atom is three times that of the $\mathrm{Sn}$ atom, which is the same as the atomic ratio of the 


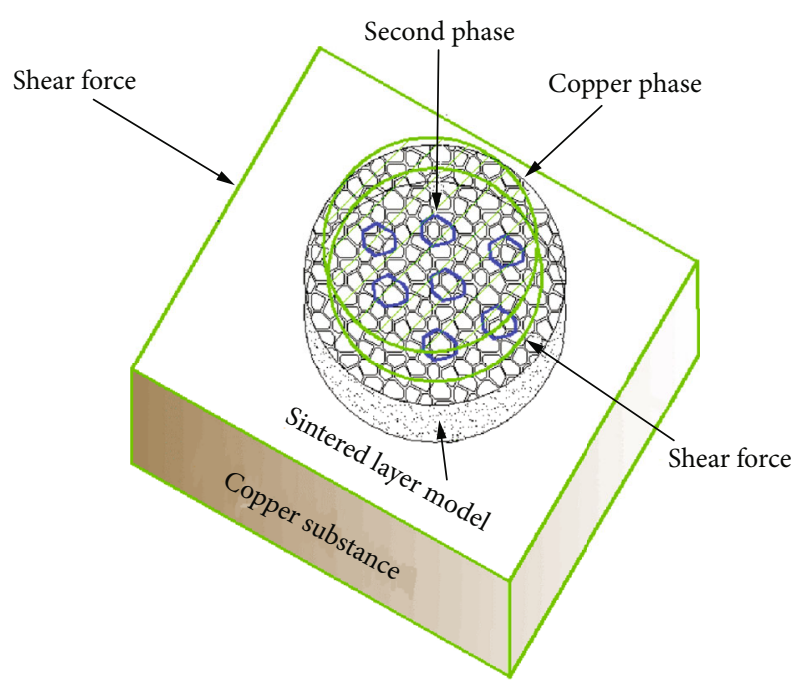

Figure 7: Dispersion strengthening model.

compound $\mathrm{Ag}_{3} \mathrm{Sn}$. Therefore, it can be inferred that the final product of the sintered silver tin paste is composed of $\mathrm{Ag}$ and $\mathrm{Ag}_{3} \mathrm{Sn}$, and this mixture promotes the sintering performance of the silver tin paste.

3.3. Strengthening Mechanism. Through experiments and references, it is concluded that the improvement of the sinter strength of silver tin paste joint may be due to the following two mechanisms: (1) dispersion strengthening and (2) displacement solid solution mechanism.

3.3.1. Dispersion Strengthening. Figure 5 shows an XRD pattern of the joints of each silver tin pastes. It can be seen from the figure that the position and intensity of the diffraction peak of silver are basically unchanged in various silver tin pastes, and the intensity of $\mathrm{Ag}_{3} \mathrm{Sn}$ diffraction peak increases with the increase of tin content, indicating the content of intermetallic compound $\mathrm{Ag}_{3} \mathrm{Sn}$ also increases accordingly. So far, we can determine that the phase in Figure 3(a) is $\mathrm{Ag}_{3} \mathrm{Sn}$.

The formation of $\mathrm{Ag}_{3} \mathrm{Sn}$ is produced by a series of processes such as melting, diffusion, reaction, and solidification. $\mathrm{The}_{\mathrm{Ag}} \mathrm{Sn}$ grain size is nanometer. As shown in Figure 6 [6], the diffraction patterns belong to $\mathrm{Ag}$ and $\mathrm{Ag}_{3} \mathrm{Sn}$, respectively. The clearer the pattern, the more perfect the crystals at the corresponding point. The $\mathrm{Ag}_{3} \mathrm{Sn}$ pattern detected at different locations indicates that $\mathrm{Sn}$ is uniformly dispersed in the slurry. The morphology and distribution of $\mathrm{Ag}_{3} \mathrm{Sn}$ grains conform to the characteristics of the dispersed strengthening phase, and $\mathrm{Ag}_{3} \mathrm{Sn}$ has hard and brittle properties. Therefore, we can infer that the $\mathrm{Ag}_{3} \mathrm{Sn}$ grains act as an ultrafine secondphase insoluble in the matrix in the silver tin paste [7], which acts as a dispersion strengthening. Figure 7 is a conceptual second-phase dispersion strengthening model which, as shown, prevents the growth of the grains and limits the movement of dislocations. When the joint is subjected to shearing force, $\mathrm{Ag}_{3} \mathrm{Sn}$ acts to prevent shearing.

3.3.2. Replacement Solid Solution Strengthening. According to the phase diagram of the silver-tin binary alloy, the equi-

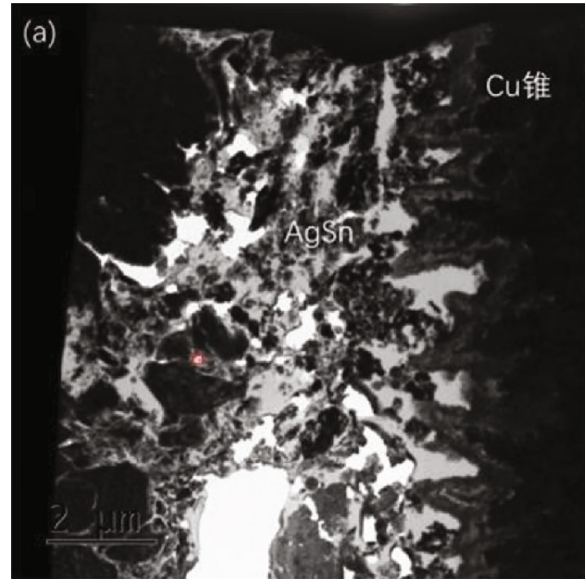

(a)

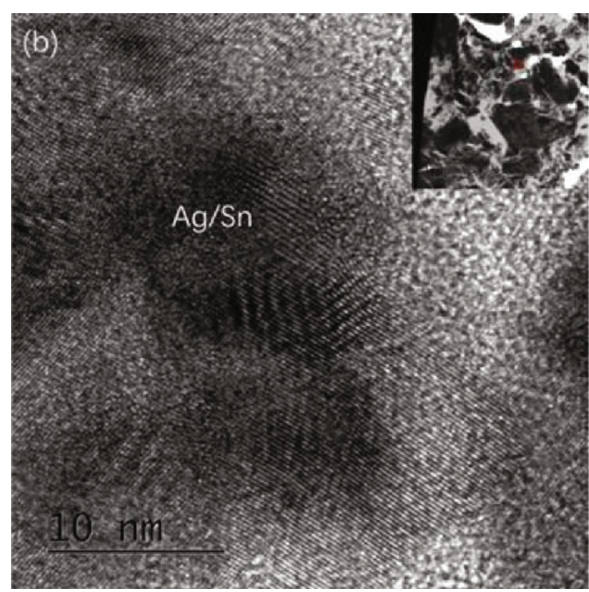

(b)

Figure 8: Transmission electron microscope image of silver+5\%tin sintered joint.

librium phase formed after sintering the silver tin paste has a solid solution of $\mathrm{Ag}$ and the intermetallic compound IMC, as shown in Figure 8 which shows the TEM image of the $\mathrm{Ag}+5 \% \mathrm{Sn}$ sintered layer [8]. Figure 8(a) demonstrated that silver is uniformly scattered throughout the sintered layer in the TEM image. Figure 8(b) demonstrated that $\mathrm{Sn}$ is uniformly scattered over the lattice of the $\mathrm{Ag}$ matrix, replacing the position of the silver atoms. Therefore, $\mathrm{Sn}$ is dissolved in silver to form a silver-based replacement solid solution.

For the silver-based displacement solid solution, tin acts as a solute atom, replacing the position of the $\mathrm{Ag}$ atom, resulting in lattice distortion of $\mathrm{Ag}$, which pinches dislocations and makes slippage difficult to continue. These increase the resistance to dislocation movement and resist the shear force. The radius of tin and silver ions is similar. After replacement, the strength of the solder can be increased gently, and the toughness and plasticity are not affected [9].

However, when the content of $\mathrm{Sn}$ is more than $5 \%$, the shear strength becomes small, and when the content of $\mathrm{Sn}$ reaches $20 \%$, it is lowered to $25 \mathrm{MPa}$ or less. The decrease in shear strength may be due to the excessive formation of the brittle hard $\mathrm{Ag}_{3} \mathrm{Sn}$ phase [8], which results in a decrease 
in the elastic properties of the joint and weakens the strength of the joint.

\section{Conclusion}

(1) In order to reduce the sintering temperature and increase the sintering strength of the nanosilver, we have developed a tin-doped nanosilver paste. When the $\mathrm{Sn}$ content is $5 \%$ and the sintering temperature is $300^{\circ} \mathrm{C}$, the joint performance is the best

(2) The sintering strength of silver tin paste increases significantly with the increase of Sn content. When the Sn content reaches 5\%, the shear strength of the joint is the highest, $50 \mathrm{MPa}$, which is higher than the pure nanosilver paste sintered joint by more than $10 \mathrm{MPa}$. However, when the content of nanotin is less than or more than $5 \%$, the sintering strength of the silver tin paste becomes small, and when the Sn content reaches $20 \%$, it is lowered to $25 \mathrm{MPa}$ or less

(3) Analysis of the sintered joint of 5\% tin-doped nanosilver shows that the shear strength is improved because the equilibrium phase produced after sintering is Ag-Sn-substituted solid solution and intermetallic compound $\mathrm{Ag}_{3} \mathrm{Sn}$, which, respectively, replace the role of solid solution strengthening and dispersion strengthening

Therefore, the newly developed tin-doped nanosilver technology not only reduces the sintering temperature but also improves the sintering strength and meets the characteristics of low-temperature sintering and high-temperature service, so it has the potential to be widely used in power semiconductor devices.

\section{Data Availability}

The data used to support the findings of this study are available from the corresponding author upon request.

\section{Conflicts of Interest}

The authors declare that they have no conflicts of interest.

\section{References}

[1] Z. Wang, Preparation and Characterization of Copper-Tin CoreShell Nanoparticles, Harbin Institute of Technology, 2015.

[2] S. Wang, J. Hongjun, L. Mingyu, and C. Wang, "Research on low temperature pressureless sintering connection ofnano silver paste for electronic packaging," Electronic Technology, vol. 11, pp. 317-319, 2012.

[3] C.-X. Yang, X. Li, G.-Q. Lu, and Y.-H. Mei, "Enhanced pressureless bonding by tin doped silver paste at low sintering temperature," Materials Science \& Engineering A, vol. 660, pp. 71-76, 2016.

[4] X. Longhua, Anti-friction Properties and Tribological Chemistry of Flake Inorganic Nanoparticles as Lubricant Additives, South China University of Technology, 2013.
[5] L. Wei, S. Qingyuan, L. Qian, Z. Sumin, and Z. Peihua, "Preparation of soluble starch/ $\beta$-cyclodextrin composite nanospheres," Journal of Dalian Polytechnic University, vol. 12, pp. 309-312, 2008.

[6] L. Zhihui, Research on Process Optimization of Chip Interconnection by Silver Paste Sintering, Central South University, 2019.

[7] B. Cunji, M. Xie, D. Wenjia, Z. Liguang, Y. Yang, and Z. Jiming, "Effect of cooling rate on morphology and distribution of Ag3Sn intermetallic compounds in Sn-3.5Ag solder," Rare Metals, vol. 3, pp. 363-370, 2014.

[8] T. Takahashi, S. Komatsu, H. Nishikawa, and T. Takemoto, "High-temperature resistant intermetallic compound joints for Si chips and $\mathrm{Cu}$ substrates," Journal of Electronic Materials, vol. 39, no. 10, pp. 2274-2280, 2010.

[9] S. Xue, Q. Yiyu, and X. Hu, "The role and mechanism of elemental tin and indium in silver-based solders," Welding, vol. 11, pp. 28-31, 1998. 


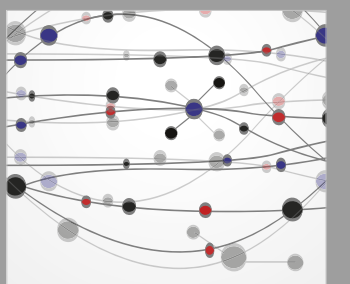

The Scientific World Journal
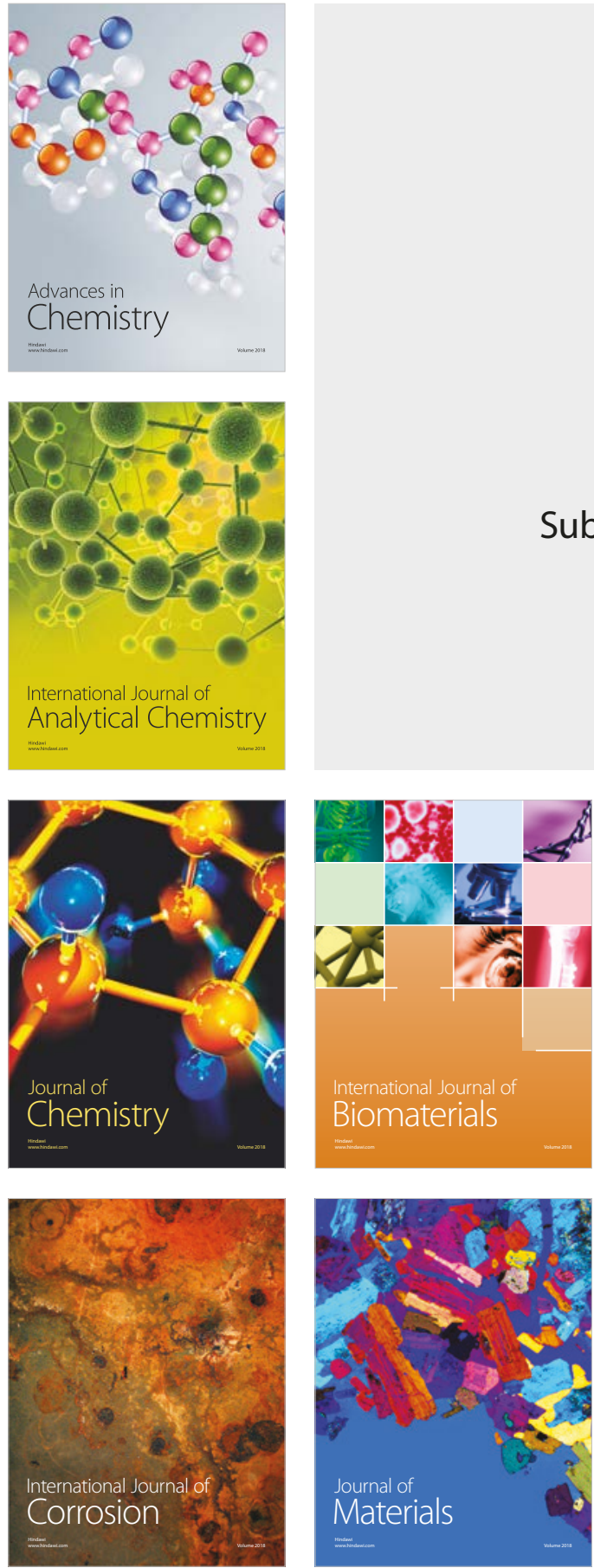

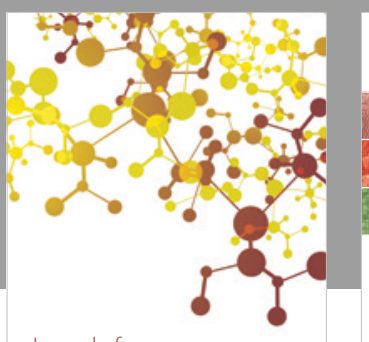

Journal of

Applied Chemistry
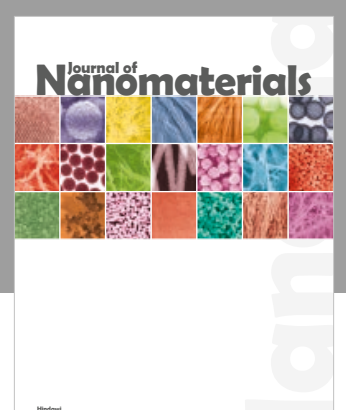

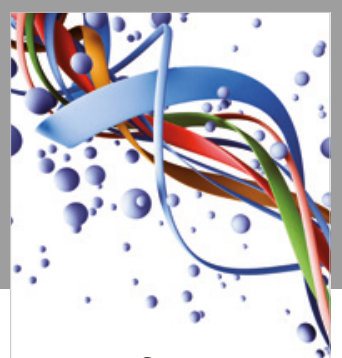

Scientifica

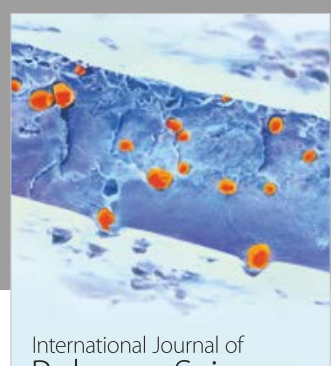

Polymer Science

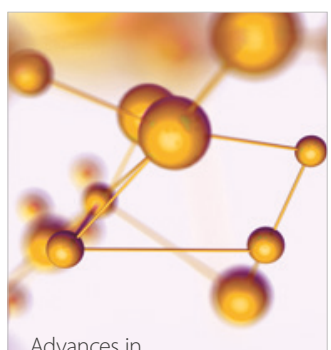

Physical Chemistry
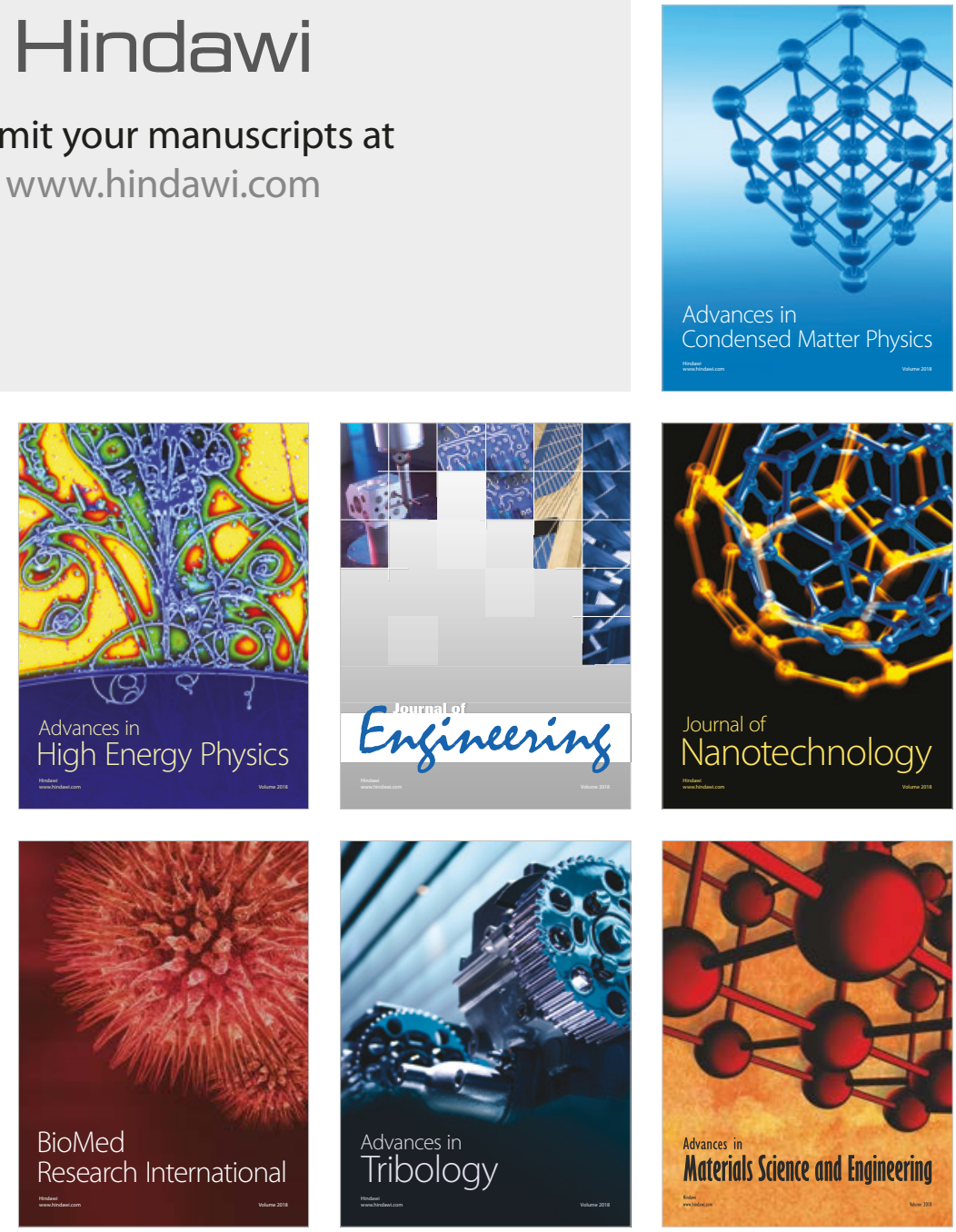